\title{
PREVALÊNCIA DE SALMONELLA SP. EM CALOPSITAS (NYMPHICUS HOLLANDICUS) MANTIDAS EM CATIVEIRO COMERCIAL
}

\section{(Prevalence of Salmonella sp. in cockatiels (Nymphicus hollandicus) kept in commercial captivity)}

\author{
Andressa Pereira Dlugosz ${ }^{1}$, Elizabeth Santin, Ricardo Mitsuo Hayashi, Mariana Camargo \\ Lourenço, Andreia Bueno da Silva \\ ${ }^{1}$ Correspondência: andressa.dlugosz@hotmail.com
}

RESUMO: Os psitacídeos estão cada vez mais próximos do ser humano devido à facilidade de manutenção que a espécie demanda. Portanto, a preocupação sanitária deve ser crescente, uma vez que as aves são reservatórios naturais de bactérias Gram negativas, como salmonelas, por exemplo. Sob condições de estresse, aves portadoras destas bactérias podem eliminar estes agentes nas fezes e dessa forma transmitir doenças, muitas delas zoonóticas como as salmoneloses para outros animais e seres humanos. O objetivo deste trabalho foi avaliar a presença de Salmonella sp. nas fezes de calopsitas (Nymphicus hollandicus) mantidas em cativeiro. Analisou-se através de cultura bacteriana um total de 129 amostras, sendo 86 suabes cloacais e 43 fezes presentes no fundo das gaiolas. Nenhuma amostra foi positiva para o agente.

Palavras-chave: psitaciformes; salmoneloses; saúde pública

ABSTRACT: The parrots are getting closer to the human being due to the ease of maintenance that the species demand. Therefore, health concern should be increased, since the birds are natural hosts of Gram-negative bacteria as salmonellas. Under stress conditions, these birds may spread the agent in the feces and thereby transmit diseases for other animals and human. The aim of this study was to evaluate the presence of Salmonella spp. in the feces of cockatiels (Nymphicus hollandicus) kept in captivity. Using bacterial culture a total of 129 samples, 86 cloacal swabs and 43 stool present in the bottom of the cages were analysed. No sample was positive for the agent.

Key Words: psittaciformes; salmonellosis; public health 


\section{INTRODUÇÃO}

Os psitaciformes são atualmente animais de estimação populares devido sua inteligência, habilidade, além da facilidade de manutenção da espécie em pequenos ambientes. Dentre os mais procurados estão os periquitos australianos (Melopsittacus undulatus), calopsitas (Nymphicus hollandicus) e papagaios (Amazona aestiva). Contudo, a ausência de estímulos ambientais adequados gerados pelo confinamento pode predispor esses animais a quadros característicos de estresse, deixando-os susceptíveis ao desencadeamento de várias doenças.

Dentre as enfermidades que afetam aves submetidas a situações de estresse, destacam-se as salmoneloses. Bactérias do gênero Salmonella sp. afetam uma grande diversidade de animais, tais como os insetos, répteis, aves e mamíferos, incluindo os seres humanos. Atualmente são conhecidos mais de 2500 sorotipos de Salmonella sp, mas aproximadamente 90 são os mais comuns e descritos em casos de infecção de seres humanos e animais. É uma bactéria de difícil controle, pois sobrevive a uma larga escala de temperatura e $\mathrm{pH}$. São amplamente distribuídos geograficamente, podendo ser encontrados no solo, água, plantas, bem como no trato gastrointestinal dos animais e permanecer nesses ambientes por longos períodos (Berchieri Júnior e Macari, 2000).

O conhecimento sobre a ocorrência e a distribuição de Salmonella sp. em animais domésticos e silvestres é essencial para relacionar os possíveis reservatórios que possam ser responsáveis pela transmissão deste agente (Dáoust et al., 2001).

A infecção geralmente progride de forma assintomática e as aves tornam-se portadoras subclínicas, eliminando contínua ou intermitentemente o agente nas fezes (Flammer, 1999).
A infecção por Salmonella em psitacídeos é relativamente comum e geralmente incapaz de produzir sinais clínicos em aves saudáveis. Porém, sob condições de aglomeração, desnutrição, más condições de higiene, dentre outros, pode levar a uma grave doença sistêmica, com altas taxas de mortalidade, especialmente em aves jovens. (Piccirillo et al.,2010).

Tendo em vista a proximidade de seres humanos com essas espécies animais, a preocupação sanitária é crescente, pois muitas doenças bacterianas acometem os psitacídeos, determinando principalmente alterações gastrintestinais, e podem transformar essas aves em fontes de zoonoses. Este estudo teve como objetivo avaliar a presença de Salmonella sp. em amostras fecais de psitacídeos mantidos em cativeiro na região metropolitana de Curitiba-PR.

\section{MATERIAL E MÉTODOS}

As coletas foram realizadas no Laboratório de Criação e Incubação de Animais Alternativos, Silvestres e Exóticos (LACRIAS), na Fazenda Experimental Canguiri da Universidade Federal do Paraná, localizada na região metropolitana de Curitiba-PR. Para o presente estudo, foram utilizadas 86 aves (Nymphicus hollandicus) entre $01 \mathrm{e}$ 03 anos de idade. As coletas foram realizadas nos meses de junho e julho de 2013. Todos os indivíduos amostrados estavam clinicamente sadios, porém sujeitos a estresses por estarem próximos de recintos onde havia outras aves, pela contenção a que foram submetidas, mas principalmente por serem aves advindas de apreensão pelo Instituto Brasileiro do Meio Ambiente e Recursos Naturais Renováveis (IBAMA).

Os animais estavam mantidos em gaiolas, cada uma contendo duas aves, sendo um macho e uma fêmea para que 
houvesse a reprodução. As gaiolas estavam posicionadas lado a lado e o manejo era realizado duas vezes ao dia, onde as aves recebiam alimentação composta por ração e mistura contendo: ovos cozidos moídos com farinha de milho, maçã e cenoura. Também eram fornecidas sementes como painço, girassol, aveia, niger, alpiste e colza. As sementes eram trocadas ou repostas uma vez por semana. As aves tinham acesso à água ad libitum e a limpeza das gaiolas e instalação feita diariamente no período da manhã.

Para realização das coletas, foram utilizados os seguintes materiais: microsuabes específicos para a espécie, tubos de ensaio estéril, potes para coleta de fezes, luvas de procedimento e preparo de solução de água peptonada $2 \%$.

As amostras foram obtidas por suabe cloacal e fezes presentes no fundo das gaiolas. Optou-se pelos dois métodos de coleta, para que fosse possível o melhor isolamento do agente.

As coletas com micro-suabes foram realizadas de maneira segura, fazendo a contenção física do animal, cuidando durante a contenção, para que o tórax da ave não fosse comprimido, possibilitando o movimento do esterno, para evitar riscos de asfixia e morte (Benez, 2004). O suabe cloacal foi imediatamente inserido no tubo de ensaio contendo $2 \mathrm{~mL}$ de água peptonada $2 \%$, solução utilizada como pré-enriquecimento. Logo após cada coleta, as amostras foram devidamente identificadas, acondicionadas sob refrigeração $\left( \pm 4^{\circ} \mathrm{C}\right)$ As amostras de fezes, em uma quantidade de aproximadamente $10 \mathrm{~g}$ foram coletadas do fundo de cada gaiola com a mão enluvada e colocadas em frasco estéril. As amostras foram identificadas e acondicionadas sob refrigeração $\left( \pm 4^{\circ} \mathrm{C}\right)$. $\mathrm{Em}$ seguida o material foi enviado ao Laboratório de Microbiologia e Ornitopatologia da Universidade Federal do Paraná (UFPR) para processamento por análise microbiológica para enriquecimento seletivo e isolamento do agente.

Os procedimentos das análises e as avaliações foram realizados utilizando os parâmetros preconizados pelo Ministério da Agricultura, Pecuária e Abastecimento (MAPA) Instrução Normativa № 62, de Agosto de 2003.

Todas as amostras em meio de água peptonada $2 \%$ foram mantidas em estufa microbiológica a $36 \pm 10 \mathrm{C}$ de 16 à 24 horas. No dia seguinte, foram homogeneizados e submetidos ao enriquecimento seletivo em caldo Tetrationato e caldo RappaportVassiliadis e incubados a $42^{\circ} \mathrm{C} \pm 1^{\circ} \mathrm{C}$ por um período de 18 a 24 horas (adaptado por Pickler et al., 2012). Para aumentar a seletividade do caldo Tetrationato, foram incluídos $2 \mathrm{~mL}$ de iodeto de potássio e 1 $\mathrm{mL}$ de caldo verde brilhante. Após o período de incubação, as amostras foram semeadas em placas de petri contendo 0 meio verde brilhante, acrescido de novobiocina. As placas foram incubadas a $36 \circ \mathrm{C} \pm 1^{\circ} \mathrm{C}$ durante 24 horas para 0 isolamento e identificação do agente. A confirmação da Salmonella foi realizada submetendo-se as colônias típicas e atípicas a testes bioquímicos em tubos contendo ágar tríplice açúcar ferro inclinado (TSI) e ágar lisina ferro inclinado (LIA), que foram incubados a $37^{\circ} \mathrm{C} / 24 \mathrm{~h}$. Confirmando-se a suspeita do gênero, as colônias foram submetidas ao teste rápido de aglutinação em lâmina, com soro polivalente anti-antígeno somático $\mathrm{O}$.

\section{RESULTADOS E DISCUSSÃO}

Dentre os animais utilizados, não houve isolamento da bactéria Salmonella sp. em amostras submetidas ao enriquecimento seletivo e provas bioquímicas, conforme Tabela 1 . 
Tabela 1- Descrição dos resultados das

análises de cultura bacteriana para

presença de Salmonella sp.

\begin{tabular}{lccc}
\multicolumn{1}{c}{ Amostra } & Identificação & Isolamento negativo & Is olamento positivo \\
\hline Suabe Cloacal & Machos & 43 & 0 \\
Suabe Cloacal & Fêmeas & 43 & 0 \\
Fezes & Gaiolas & 43 & 0 \\
Total & & 129 & 0
\end{tabular}

Os

\section{resultados}

obtidos

demonstram a baixa prevalência no isolamento da bactéria. Alguns autores, como Lopes et al. (2011) pesquisaram, por suabe cloacal e cultivo, a ocorrência de Salmonella sp. em aves silvestres de vida livre e cativeiro no Estado de São Paulo e isolaram o agente em 1,65\% das amostras. Corrêa et al. (2013) analisaram amostras de 44 psitacídeos de cativeiro, das quais nenhuma foi positiva para Salmonella sp. reforçando a dificuldade no isolamento do agente. Gopee et al. (2000) citam que aves de vida livre são apontadas como potenciais carreadoras de patógenos para o interior de plantéis de animais, mas que a frequência de Salmonella sp. em aves de cativeiro é relativamente baixa, quando comparada a mamíferos e répteis. Em estudo realizado no município de Araçatuba- SP, foram avaliados 50 papagaios-verdadeiros mantidos em cativeiro domiciliar e não foi isolada Salmonella sp. em nenhuma amostra de fezes (Bonello, 2006). Outro estudo realizado na região do Pantanal, por Allgayer et al. (2009), avaliaram 14 filhotes de arara-azul; as amostras foram coletadas com suabe cloacal e uma ave foi positiva para Salmonella sp. O mesmo autor em 2002 avaliou o soro de 60 psitacídeos mantidos em cativeiro para S. pullorum no Brasil, sendo todas as aves negativas. Mesmo tendo em vista os resultados negativos para o agente, é importante salientar que a transmissão desta zoonose, embora seja mais descrita pela ingestão de alimento contaminado, também pode ocorrer através do contato direto com os animais, especialmente para crianças, quando a bactéria é facilmente levada à boca (Flamer, 1999).
Marietto-Gonçalves et al. (2010) relataram o primeiro caso de Salmonella enteritidis em Amazona aestiva oriundos do tráfico de animais silvestres em São Paulo e esses mesmos autores analisaram 89 amostras de suabes cloacais de três espécies diferentes de psitacídeos, onde isolou-se apenas uma amostra de Salmonella sp. Nesta espécie, representando 1,12\% (1/89) do material analisado.

A Salmonella sp. é uma bactéria altamente invasiva nas aves, uma vez que entra por via oral e atinge rapidamente o intestino onde coloniza a mucosa (especialmente nos cecos) e invade a corrente sanguínea para chegar até os órgãos viscerais como fígado, baço e ovário. Uma vez infectadas, as aves tornam-se para sempre portadoras, eliminando $o$ agente nas fezes sob condições de estresse e imunossupressão, permitindo que 0 agente permaneça no ambiente por longos períodos e assim ocorra a transmissão via fecal-oral tanto para animais, como para seres humanos.

Pode-se sugerir que a boa condição de saúde das aves, associado a boa alimentação das mesmas e ótimo bem estar em que se encontravam, resulta em uma ótima homeostase de microbiota que compete com a presença de Salmonella. A microbiota normal na maioria dos psitacídeos consiste em bactérias Gram positivas, e as bactérias Gram negativas como: Escherichia coli, Enterobacter, Klebsiella, Pseudomonas, Salmonella, Proteus, Pasteurella, Campylobacter e Chlamydophila psittaci (Oglesbee e Bishop, 1998). Porém, Salmonella sp. é uma bactéria intracelular facultativa e que, mesmo infectando o hospedeiro, pode não ser eliminada nas fezes devido a fatores individuais, ou nutricionais, havendo a possibilidade de ocorrer resultados falsos negativos.

O Programa Nacional de Sanidade Avícola preconiza a realização 
de suabe cloacal para a monitoria de Salmonella sp. em aves domésticas, silvestres e ornamentais (Brasil, 2006). O diagnóstico deve ser realizado com base no isolamento e identificação do agente, porém provas sorológicas podem ser utilizadas para a identificação de aves que têm ou tiveram contato com salmonelas paratíficas (Gast, 2003). Grimes \& Arizmedi (1992) observaram $1,6 \%$ de positividade para $S$. Typhimurium, ao analisarem 2.407 amostras de psitacídeos através de soroaglutinação. Em estudo realizado no zoológico Quinzinho de Barros/Sorocaba, para avaliar a presença de Salmonella nas fezes de aves selvagens, observou-se que $11 \%$ das amostras foram positivas para 0 agente (Schubert, 2008). Essa variabilidade deve estar muito associada a origem das aves e as condições de estresse e nutricionais as quais estão submetidas.

Sabe-se que as aves uma vez infectadas com Salmonella, tornam-se portadoras, ficando a bactéria albergada dentro de macrófagos em vísceras como fígado e baço, porém só eliminarão o agente nas fezes quando estiverem imunossuprimidas ou sob condições de estresse, 0 que torna possível a ocorrência de resultados falsos negativos na análise microbiológica. Sendo assim, não pode ser descartada a hipótese de que as aves negativas na cultura bacteriana sejam positivas para o agente. Portanto é necessário a realização de novos estudos sobre o isolamento de Salmonella em aves silvestres.

\section{CONCLUSÃO}

Não foi possível o isolamento de Salmonella sp. em psitacídeos clinicamente sadios mantidos em cativeiro utilizando a técnica microbiológica convencional. Os resultados, entretanto, não confirmam que as aves não sejam infectadas pelo agente, pois seriam necessárias técnicas mais invasivas para confirmar a negatividade para 0 agente. Como medida de prevenção de eliminação do agente e o potencial zoonótico destes animais, o suabe de cloaca e análise de fezes pode ser uma boa ferramenta.

\section{AGRADECIMENTOS}

Ao Laboratório de Criação e Incubação de Animais Alternativos, Silvestres e Exóticos (LACRIAS) e ao Laboratório de Microbiologia e Ornitopatologia (LABMOR) da Universidade Federal do Paraná.

\section{Nota Informativa}

Este trabalho foi aprovado pelo comitê de ética sob o número 039/2014.

\section{REFERÊNCIAS}

ALLGAYER, M.C.; MORAES, H.L.S.; ANDELIERI, S.L. et al. Avaliação sorológica para verificação de infecção natural de Salmonella pullorum em psitacídeos do criadouro Asas do Brasil. In: CONGRESSO DA SOCIEDADE DE ZOOLÓGICOS DO BRASIL, 26., 2002 Porto Alegre. Anais... Porto Alegre, 2002. p. 128.

ANDREATTI FILHO, R.L. Saúde aviária e doenças. São Paulo, SP: Roca, 2006. p. 84-96.

ALLGAYER, M.C.; OLIVEIRA, S.J.; MOTTIN, V.D. et al. Isolamento de Salmonella braenderup em arara-azul (Anodorhynchus hyacinthinus). Ciência Rural, v.39, p.2542-2545, 2009.

BERCHIERI JÚNIOR, A.; MACARI, M. Doenças das aves. Campinas: Facta, 2000. p.185.

BONELLO, F.L. Investigação de Salmonella sp. em psittaciformes mantidos em criatórios comerciais e conservacionistas da região metropolitana de Fortaleza-CE. 68 f. Dissertação (Mestrado em Ciências Veterinárias) - Faculdade de Veterinária da Universidade Estadual do Ceará, Fortaleza, 2011. 
BRASIL. Ministério da Agricultura Pecuária e Abastecimento. Instrução Normativa n. 62. Diário Oficial da República Federativa do Brasil, Brasília, 26 ago. 2003. Seção 1, p. 14.

BRASIL. Ministério da Agricultura, Pecuária e Abastecimento. Secretaria de Defesa Agropecuária. Instrução Normativa conjunta n. 78. Diário Oficial da República Federativa do Brasil, Brasília, n. 215, 5 jan. 2003.

CORRÊA, I.M.O.; FLORES, F.; SCHNEIDERS, G.H. et al. Detecção de fatores de virulência de Escherichia coli e análise de Salmonella spp. em psitacídeos. Pesquisa Veterinária Brasileira, v. 33, p.241-246, 2013.

D'AOUT, J.Y.; MAURER, J.; BALEY, J.S. Salmonella Species. In: DOYLE, M.P.; BEUCHAT L.R. Food Microbiology Fundamentals frontiers. 2.ed. Washington, DC: American Society for Microbiology, 2001. p.141-178.

FLAMMER, K. Zoonosis Acquired from Birds. In: FOWLER, M.E.; MILLER, R.E. (Eds). Zoo and wild animal medicine: current therapy. Philadelphia: W.B. Saunders, 1999. p.151-156.

GAST, R.K. Salmonella infections. In: SAIF, Y.M.; BARNES, H.J.; GLISSON, J.R. et al. (Eds). Diseases of Poultry. 11th ed. Ames: lowa State Press, 2003. p.567-613.

GOPEE, N.V.; ADESIYUN, A.A.; CAESAR. K. Retrospective and longitudinal study of salmonellosis in captive wildlife in Trinidad. Journal of Zoo and Wildlife Medicine, v.36,p.284293, 2000.

GRIMES, J.E.; ARIZMENDI, F. Survey of clinical psittacine bird sera for Salmonella typhimurium agglutinins. Avian Diseases, v.36, p.813$815,1992$.

LOPES, E. S. Investigação de Salmonella sp. em psittaciformes mantidos em criatórios comerciais e conservacionistas da região metropolitana de Fortaleza- CE. 71 f. Dissertação (Mestrado em Ciências Veterinárias) - Universidade Estadual do Ceará, Fortaleza, 2011.

MARIETTO, G.G.A.; ALMEIDA, S.M.; LIMA, E.T. et al. Detecção de Escherichia coli e Salmonella sp. em microbiota intestinal de Psittaciformes em fase de reabilitação para soltura. Brazilian Journal of Veterinary Research and Animal Science, v.47, p.185-189, 2010.

OGLESBEE, B.L.; BISHOP, C.L. Doenças infecciosas aviárias. In: BISHARD, S.J.; SHERDING, R.G. Manual Saunders: clínica de pequenos animais. São Paulo: Roca, 1998. p.1404-1419.

PICCIRILLO, A.; MAZZARIOL, S.; CALIARI, D. et al. Salmonella typhimurium Phage Type DT160
Infection in Two Moluccan Cockatoos (Cacatua moluccensis): Clinical Presentation and Pathology. Avian Diseases, v.54, n.1, p.131-135, 2010.

PICKLER, L.; HAYASHI, R.M. LOURENÇO, M.C. et al. Avaliação microbiológica, histológica e imunológica de frangos de corte desafiados com Salmonella enteritidis e Minnesota e tratados com ácidos orgânicos. Pesquisa Veterinária Brasileira, v.32, p.27-36, 2012.

SCHUBERT, M.A.R. Isolamento de salmonella spp de amostras fecais de aves silvestres mantidas em cativeiro. 27 p. Trabalho de Graduação (Bacharel em Medicina Veterinária) Faculdades Metropolitanas Unidas, São Paulo, 2008. 